\title{
Cerebrospinal Fluid Proteomic Changes in Older Non-Cardiac Surgical Patients with Postoperative Cognitive Dysfunction
}

\section{Keith W. VanDusen}

Duke University https://orcid.org/0000-0002-8197-8734

Wenjing Qi

Duke University

Yi-ju Li

Duke University

\section{Victor Cai}

Duke University

\section{Ashley Hall}

Duke University

\section{Sarah Hiles}

Duke University

J. Will Thompson

Duke University

M. Arthur Mosely

Duke University

Jessica Hu

Duke University

Mary Cooter

Duke University

Leah Acker

Duke University

Jerrold H. Levy

Duke University

Kamrouz Ghadimi

Duke University

Quintin J. Quiñones

Duke University

Michael J. Devinney

Duke University

Niccolò Terrando 
Duke University

Eugene W. Moretti

Duke University

Jeffrey N. Browndyke

Duke University

Joseph P. Mathew

Duke University

Miles Berger ( $\nabla$ miles.berger@duke.edu )

\section{Research}

Keywords: Unbiased Proteomics, Mass Spectrometry, Postoperative Cognitive Dysfunction, Perioperative Neurocognitive Disorders

Posted Date: June 18th, 2020

DOI: https://doi.org/10.21203/rs.3.rs-35959/v1

License: (c) (i) This work is licensed under a Creative Commons Attribution 4.0 International License. Read Full License 


\section{Abstract}

Background: Postoperative cognitive dysfunction (POCD) is a syndrome of cognitive deficits that occurs in $10-40 \%$ of patients age $>60$ within $1-12$ months after surgery, hypothesized to be caused in part by neuroinflammation. However, the specific neuroinflammatory pathways involved remain unclear. Unbiased mass spectrometry-based proteomic analyses have been used to identify neuro-inflammatory pathways in multiple neurologic diseases and syndromes but have not yet been used in the POCD field. Thus, we used unbiased mass spectrometry-based proteomics to compare cerebrospinal fluid (CSF) samples from patients with and without POCD to identify potential neuroinflammatory pathways for further investigation in future studies.

Methods: We performed unbiased LC-MS/MS proteomics on immunodepleted CSF samples obtained before, 24 hours, and 6 weeks after major non-cardiac surgery in older adults who developed $(n=8)$ or did not develop POCD $(n=6)$. General linear mixed models were used to identify peptides and proteins with intensity differences between groups or over time by groups. Kyoto Encyclopedia of Genes and Genomes analysis was used to identify pathways containing proteins/peptides with q values $<0.25$ in the mixed model.

Results: Mass spectrometry quantified 8258 peptides from 1222 proteins in $>50 \%$ of patient samples at all three time points. Twelve peptides from 11 proteins showed differences in expression over time between groups (POCD vs non-POCD) at $\mathrm{q}<0.05$, including several from proteins previously implicated in neurodegenerative disease pathophysiology. Additionally, 283 peptides from 182 proteins were identified with trend-level differences $(q<0.25)$ in expression over time between these patient groups. Of these 283 peptides with trend-level significance, pathway analysis revealed that 50 of them were from 17 proteins that mapped to the complement and coagulation pathways $\left(q=2.44^{\star} 10^{-13}\right)$.

Conclusions: These data demonstrate the feasibility of performing unbiased mass spectrometry on perioperative CSF samples to identify peptides, proteins, and pathways associated with POCD.

Additionally, they provide hypothesis-generating evidence for CSF complement and coagulation pathway changes in patients with POCD.

\section{Background}

Postoperative cognitive dysfunction (POCD) is a perioperative neurocognitive disorder characterized by a decrease of at least one standard deviation in measured cognitive function from baseline to 112 months after surgery. POCD, also referred to as neurocognitive disorder, postoperative when accompanied by subjective cognitive complaints or impaired ability to perform activities of daily living, occurs in up to $40 \%$ of older surgical patients[1-3] and is associated with decreased postoperative quality of life[4, 5], poor long-term cognitive outcomes[6], and elevated 1-year mortality[7]. With an aging population and over 16 million patients undergoing surgery each year in the U.S., POCD and other perioperative neurocognitive disorders constitute a growing public health concern[8]. 
Currently, prevention and treatment of POCD and other perioperative neurocognitive disorders remain limited by our incomplete understanding of their underlying mechanisms. These conditions are hypothesized to result from dysregulated immunity, including postoperative neuroinflammation, partly because neuroinflammation has been associated with cognitive deficits in preclinical models and several other neurocognitive disorders including Alzheimer's disease (AD) (reviewed)[9], Multiple Sclerosis[10, 11], and Autoimmune Encephalitis[11]. Indeed, patients with POCD exhibit elevated cerebrospinal fluid (CSF) inflammatory cytokines[12-14], microglial activation[15], blood-brain barrier dysfunction[16], and exacerbation of pre-existing AD-related pathology $[14,17,18]$. Many POCD biomarker studies have utilized targeted assays measuring specific proteins and inflammatory markers in blood and/or CSF samples before and after surgery[18-22]; however, these antibody-based targeted assays limit investigation to narrow ranges of prespecified proteins, lacking the ability to identify novel proteins or pathways that may be involved in POCD.

In contrast to antibody-based assays, mass spectrometry-based approaches offer proteome-wide characterization by comparing peptide fragment intensities after a proteolytic preparation step. These intensities provide relative concentration measurements for thousands of peptide analytes, which are subsequently matched to their parent proteins. Though lacking the precision of targeted assays, mass spectrometry-based proteomics offer an ability to identify novel protein targets and pathways underlying disease states in a hypothesis-independent, "unbiased" manner. Additionally, they permit identification of specific post-translational modifications, such as phosphorylation, that may be used to assess protein activation and signal cascade involvement[23].

Previously, unbiased proteomic analyses have been successfully deployed to identify novel biomarkers for mild cognitive impairment[24], AD[24-26], frontotemporal dementia[27, 28], Parkinson's disease[29], amyotrophic lateral sclerosis[28], HIV-related cognitive impairment[30], amygdala dysfunction[31], and chronic traumatic encephalopathy[32]. Recently, they have also been applied to postoperative delirium, revealing several candidate biomarkers and patterns of CSF protein dysregulation[33]. To date, though, few other studies have utilized unbiased mass spectrometry-based proteomics to identify novel CSF protein biomarkers or pathways in older adults with perioperative neurocognitive disorders. In this pilot study, we examined the feasibility of using this approach to measure changes in CSF protein levels from patients with POCD compared to healthy controls in order to identify pathways that may contribute to POCD pathogenesis for further study.

\section{Methods}

\section{Overview \& Patient Selection}

The protocol for this study was approved by the Duke University Medical Center Institutional Review Board as part of a parent cohort study registered with clinicaltrials.gov (NCT01993836). All subjects gave written informed consent. For the parent study, we enrolled 140 English-speaking patients age 60 and above who were undergoing non-cardiac, non-neurologic surgery scheduled for at least two hours under 
general anesthesia. All patients received propofol for anesthetic induction and either propofol or isoflurane for anesthetic maintenance. There were no exclusions for preoperative cognitive status; however, all patients had to be able to complete our cognitive test battery.

\section{Cognitive testing}

All patients included in the parent study underwent neurocognitive assessment at baseline and 6 weeks after surgery using our established neurocognitive test battery $[6,34-36]$ including the Randt Short Story Test, the Wechsler Memory Scale Modified Visual Reproduction Test, the Digit Span and Digit Symbol tests from the Revised Wechsler Adult Intelligence Scale, and the Trail Making Test, Part B. The scores from these tests were reduced to uncorrelated factor scores by factor analysis with orthogonal rotation, which were derived in a previous study of similar non-cardiac surgical patients[37]. This approach derived four factor scores that corresponded to four cognitive domains: verbal memory; abstraction and visuospatial orientation; visual memory; and attention and concentration. Postoperative cognitive dysfunction was defined as $a \geq 1$ standard deviation decrease of factor scores in one or more of these four cognitive domain from baseline to 6 weeks after surgery as previously described[6, 35, 36, 38-43]. Continuous Cognitive Index (CCl) scores were subsequently calculated for each patient by averaging their scores across all four domains and mean normalizing the results to zero. Thus, the $\mathrm{CCl}$ represents a single global measurement of cognitive function, with a positive score indicating above average overall cognitive testing performance and a negative score indicating below average performance compared to the reference study population[37].

\section{Patient Selection for Proteomic Analyses}

From the 140 patients in the parent study, eight subjects with POCD, defined by a $>1$ standard deviation decrease in at least one cognitive domain from before to six weeks after surgery, and six subjects without POCD at 6 weeks after surgery were selected for inclusion in this proteomics study. We prioritized selection of patients with similar age and years of education for both groups to avoid potential confounding from these factors (Table 1).

\section{CSF and Blood Sample Collection}

Participants underwent baseline CSF and blood sampling within a month prior to surgery. Repeat CSF samples were obtained $24 \pm 2$ hours after the start of surgery and $6 \pm 3$ weeks after surgery[34, 44]. CSF was collected using our protocol for minimizing pain and adverse events associated with lumbar puncture[41, 45]. Briefly, participants' lower backs were scrubbed with sterile iodine, and $20 \%$ benzocaine was applied by spray canister. After waiting ten minutes for the local anesthetic to take effect, up to $5 \mathrm{~mL}$ of $1 \%$ lidocaine was injected subcutaneously at the targeted lumbar interspace. Subsequently, a 25-gauge spinal needle was inserted through 20-gauge introducers at the same interspace to extract approximately $10 \mathrm{~mL}$ of CSF using aseptic techniques. The puncture site was then covered with a bandage, and the patient was instructed to remain supine for at least 30 minutes to minimize the risk of post-dural puncture headache[45].

\section{CSF and Blood Sample Processing}


CSF and blood supernatant aliquots were stored at -80 degrees $C$, and initial blood samples were used for APOE genotyping by the Duke University DNA Analysis Facility (Durham, NC) using Applied Biosystems TaqMan SNP genotyping assays (10 ng DNA/assay) and an Applied Biosystems 7500 Fast Real-Time PCR system.

CSF samples ( $N=42$; one collected from each patient at each time point) were delivered to the Duke Proteomics and Metabolomics Shared Resource on dry ice, and gently thawed on ice. Coomassie Plus Bradford assays (Thermo Fisher Scientific, Waltham, MA, USA) were performed to determine protein concentrations, which varied from less than $0.125 \mathrm{ug} / \mu \mathrm{L}$ to greater than $2 \mathrm{ug} / \mu \mathrm{L} .20 \mu \mathrm{L}$ of human plasma was mixed with $730 \mu \mathrm{L}$ of Sample Dilution Buffer (Agilent Technologies, Santa Clara, CA, USA) as a CSF-mimic positive control. For experimental samples, $600 \mu \mathrm{L}$ of human CSF was mixed with $150 \mu \mathrm{L}$ High Concentration Buffer (Agilent), such that the total volume for all samples (positive control and experimental samples was $750 \mu \mathrm{L}$. The diluted samples were then centrifuged through a $0.22 \mathrm{um}$ cellulose acetate centrifugal spin filter unit (Agilent) for 3 minutes at $15,000 \mathrm{rpm}$ and $4^{\circ} \mathrm{C}$. The filtered samples were transferred to Maximum Recovery LC glass v-bottom vials (Waters Corporation, Milford, MA, USA). $725 \mu \mathrm{L}$ of each sample was immunodepleted to remove the high abundance plasma proteins using a MARS-14 LC column (Agilent) and an Agilent 1100 HPLC according to the manufacturer's protocol.

Following immunodepletion, samples were buffer exchanged with $50 \mathrm{mM}$ ammonium bicarbonate using Amicon 10 MWCO (EMD Millipore, Burlington, MA, USA). Immunodepletion was quality-control checked by analysis of pre-versus post depletion samples on 4-13\% Bis-Tris NuPAGE gel (Thermo) in MES buffer, and a Bradford protein assay of pre-versus post-depletion samples to confirm protein removal was consistent; protein removal via immunodepletion was on average $88.5 \%$. Samples were then normalized to 8 ug each and supplemented to $0.1 \% \mathrm{w} / \mathrm{v}$ Rapigest detergent (Waters) for digestion. Samples were reduced with $10 \mathrm{mM}$ dithiothreitol for $10 \mathrm{~min}$ at $80 \mathrm{C}$, alkylated with $20 \mathrm{mM}$ iodoacetamide at room temperature in the dark for 30 minutes, and digested with 1:50 trypsin:protein (Promega Sequencing Grade) overnight at 37C. After digestion, samples were acidified to 1/2/97 v/v/v TFA/MeCN/water and heated at $60 \mathrm{C}$ for 1 hour to hydrolyze Rapigest. 1 pmol ADH1_YEAST MassPrep standard (Waters) was added to each sample as a surrogate standard. Finally, a study pool QC (SPQC) sample was made by combining $5 \mathrm{uL}$ of each digested sample.

\section{Quantitative Analysis of CSF Proteins}

Quantitative one-dimensional LC-MS/MS was performed on $2 \mu \mathrm{L}(500 \mathrm{ng})$ of the protein digest per sample from all subjects in singlicate, with replicate analyses of the SPQC interspersed throughout at even intervals. Samples were analyzed using a nanoAcquity UPLC system (Waters) coupled to a Q Exactive Plus Orbitrap high resolution accurate mass tandem mass spectrometer (Thermo) via a nanoelectrospray ionization source. Briefly, the sample was first trapped on a Symmetry $\mathrm{C} 18300 \mathrm{~mm} \mathrm{x}$ $180 \mathrm{~mm}$ trapping column ( $5 \mathrm{LL} / \mathrm{min}$ at $99.9 / 0.1 \mathrm{v} / \mathrm{v} \mathrm{H} 20 / \mathrm{MeCN})$, after which the analytical separation was performed using a 1.7 um Acquity HSS T3 C18 $75 \mathrm{~mm}$ x $250 \mathrm{~mm}$ column (Waters) using a 90-min gradient of 5 to $40 \% \mathrm{MeCN}$ with $0.1 \%$ formic acid at a flow rate of $400 \mathrm{~nL} / \mathrm{min}$ with a column temperature 
of $55^{\circ} \mathrm{C}$. Data collection on the Q Exactive Plus mass spectrometer was performed in a data-dependent MS/MS manner, using a 70,000 resolution precursor ion (MS1) scan followed by MS/MS (MS2) of the top 10 most abundant ions at 17,500 resolution. MS1 was accomplished using AGC target of $1 * 10^{6}$ ions and max accumulation of $60 \mathrm{msec}$. MS2 used AGC target of $5^{\star} 10^{4}$ ions, $60 \mathrm{msec}$ max accumulation, $2.0 \mathrm{~m} / \mathrm{z}$ isolation window, $27 \mathrm{~V}$ normalized collision energy, and 20 second dynamic exclusion. The total analysis cycle time for each sample injection was approximately 2 hours, and the experiment totaled 51 injections.

Samples were run in a randomized block design, and the QC Digest Pool was analyzed after every 6th sample within the group as well as at the beginning and end of the study. Following the analyses, the data was imported into Rosetta Elucidator v4.0 (Rosetta Biosoftware, Inc., Seattle, WA, USA), and all LCMS files were aligned based on the accurate mass and retention time of detected ions ("features") using Rosetta Elucidator PeakTeller algorithm. The relative peptide abundance was calculated based on areaunder-the-curve of aligned features across all runs. The dataset had 67,076 quantified features and HCD fragmentation was performed to generate approximately $1.62 \mathrm{M} \mathrm{MS} / \mathrm{MS}$ spectra for sequencing by database searching.

\section{Peptide Identification and Inclusion}

The MS/MS data was searched against the UNIPROT protein sequence database with Homo sapiens species taxonomy, which also contained several surrogate standards sequences and common laboratory contamination proteins, as well as a reversed-sequence "decoy" database for false discovery rate determination. Amino acid modifications allowed in database searching included fixed deamidation on Asn and GIn $\left({ }^{\star}\right)$, carbamidomethyl Cys $\left({ }^{(*}\right)$, and oxidation on Met $\left({ }^{(* *}\right)$. The data was searched with 5 ppm precursor, 0.02 Da product ion tolerance, and tryptic enzyme specificity, allowing up to two missed cleavages. Data was processed to the peptideTeller data curation algorithm to determine false discovery rate and was annotated at $0.5 \%$ peptide false discovery rate.

The raw peptide intensities were then scaled across all samples using robust mean scaling. To detect outliers, principle component analysis was performed for the scaled peptide intensities. By comparing principal components 1 and 2, one sample was found outside the cluster of the rest of samples. Therefore, this sample was excluded as an outlier. Additionally, two samples were processed in duplicate to ensure agreement; peptide intensities from these samples were averaged for analysis. Peptide intensities that were missing (i.e. below the lower limit of detection) or below the 5th percentile of the nonmissing intensities of each peptide were imputed with the 5th percentile of the non-missing intensities of that same peptide. Peptides that required imputation in more than 10 samples were excluded. To remove unstable peptides or those with poor precision, peptides with greater than $40 \%$ coefficient of variation across the QC pool were also excluded. Finally, the intensities of all the peptides and proteins were log2 transformed before statistical analysis.

\section{Statistical Analysis}


Descriptive statistics were computed for key demographic and patient characteristics variables including age, sex, years of education, cognitive measures, and APOE genotypes by frequency (percentage) for categorical variable and mean (standard deviation, SD) for continuous variables. Two sample t test and Wilcoxon rank sum test were conducted to compare the log2 transformed intensity difference of each peptide and protein between subjects who did and who did not have POCD at each time point (baseline, 24 hours post operation, and 6 weeks post operation). To correct for multiple testing, q-values were computed for each peptide and protein at each time point[46]. Finally, to detect POCD effect on peptide intensity over time, linear mixed models were fitted for intensities of each peptide regressed on the fixed effects of group (i.e. POCD vs no POCD) from 24 hours and 6 weeks after surgery, time, and interaction of group and time with random intercept and slope of time. Again, q-values of POCD effect were computed for each peptide and protein to correct for multiple testing. Proteins containing peptides meeting $q<0.25$ were considered as candidates with probable POCD association.

\section{Pathway Analysis}

Pathway analysis was conducted using the Database for Annotation, Visualization and Integrated Discovery with the Kyoto Encyclopedia of Genes and Genomes pathway database. This pathway analysis was performed on genes encoding proteins that contained top candidate peptides $(q<0.25)$ selected from our linear mixed model (described above). Significant pathways were determined by Benjamini-Hochberg false discovery rates (FDR) less than $0.05(q<0.05)$ from the pathway analysis[47].

\section{Results}

\section{Patient Characteristics}

Of the 14 patients included in the study, 8 developed POCD at 6 weeks after surgery, while 6 did not. Baseline/preoperative patient characteristics are listed in Table 1. The two groups were generally similar; there was no significant difference in age, years of education, baseline cognitive index, or APOE genotype distribution between groups ( $p>0.35$ for all). $\mathrm{CCl}$ change from before to 6 weeks after surgery was worse in the POCD group than the non-POCD group, as expected (-0.147 vs $0.173, p=0.013)$. 
Table 1

Patient Characteristics

\begin{tabular}{|c|c|c|c|}
\hline Characteristic & POCD & Non-POCD & Statistics \\
\hline Number of patients & 8 & 6 & - \\
\hline Age & $71.25 \pm 7.07$ & $70.5 \pm 5.75$ & $p=0.836$ \\
\hline Percent Female & $50 \%$ & $33 \%$ & - \\
\hline Years of Education & $16 \pm 4.34$ & $16 \pm 2.19$ & $p=1.000$ \\
\hline Baseline $\mathrm{CCl}$ & $0.100 \pm 0.678$ & $-0.010 \pm 0.451$ & $p=0.738$ \\
\hline $\begin{array}{l}\text { CCl change at six } \\
\text { weeks }\end{array}$ & $-0.147 \pm 0.215$ & $0.173 \pm 0.187$ & $p=0.013$ \\
\hline $\begin{array}{l}\text { APOE Genotypes } \\
\text { Represented }\end{array}$ & $\begin{array}{l}\text { APOE- } \varepsilon 3 / 3 \text { (7), APOE- } \\
\varepsilon 2 / 3(1)\end{array}$ & $\begin{array}{l}\text { APOE- } \varepsilon 3 / 4 \text { (2), APOE- } \varepsilon 3 / 3 \text { (3), } \\
\text { APOE- } \varepsilon 2 / 3 \text { (1) }\end{array}$ & $P=0.385$ \\
\hline
\end{tabular}

Table 1. Patient characteristics for the POCD and non-POCD groups. Values are presented as mean \pm standard deviation, with p-values where appropriate. There were no significant differences in age, years of education, baseline $\mathrm{CCl}, \mathrm{CCl}$ change at six weeks, or APOE genotype distribution between POCD and nonPOCD groups. P-values for age, years of education, baseline $\mathrm{CCl}$, and $\mathrm{CCl}$ change at six weeks calculated with two-tailed t-tests. P-value for APOE genotypes calculated using a Fisher's exact test.

\section{CSF Proteome Characterization}

Initial CSF analysis identified 8258 peptides that mapped to 1222 proteins. 11 peptides were removed because they required imputation in 10 or more samples, and a small fraction (8.5\%) of peptides were removed due to $>40 \%$ variability in the SPQC replicates across the course of the study. Therefore, the final quantitative dataset consisted of 7542 peptides and 1180 proteins for statistical analysis (Supplemental Data). No peptides from any of the three time points were found to be significantly different between the two groups after accounting for multiple testing with a threshold of $q<0.05$, an unsurprising finding given the large number of peptides measured and small sample size.

\section{Repeated Measures and Pathway Analyses}

Our linear mixed model analysis on peptide intensity over time did not detect any peptides for the interaction of group by time at 24 hours post-surgery, but identified 12 peptides from 11 different proteins with statistically significant differences after FDR adjustment $(q<0.05)$ for the interaction term of group by time at 6 weeks post-surgery (Supplemental Table 1). Here, pre-surgery time was the reference. The 12 significant peptides accounted for approximately $7.3 \%$ of the 165 total peptides identified from those 11 proteins and included two different peptides from the copper carrying protein ceruloplasmin. Because our pilot study may have been underpowered to detect differences in other peptides, proteins, and pathways within a mixed model, we also examined peptides with q-values $<0.25$ as previously described[48]. There were 283 unique peptides with $\mathrm{q}<0.25$ in these linear mixed models, which mapped to 182 unique parent 
proteins (Supplemental Table 1). These 283 peptides accounted for approximately $10.5 \%$ percent of the 2694 total peptides identified derived from these 182 unique proteins.

To identify pathways that may be involved in the pathogenesis of POCD, the genes coding for these 182 proteins were mapped to functional pathways using the Kyoto Encyclopedia of Genes and Genomes (KEGG) pathway database, and pathway analysis was conducted using the Database for Annotation, Visualization, and Discovery[49,50]. This led to identification of nine pathways statistically associated at $p<0.05$ with subsets of the 182 featured proteins (Supplemental Table 1). False discovery rates were also calculated for these pathways to account for type-1 error due to multiple comparisons. Kyoto Encyclopedia of Genes and Genomes pathway hsa04610: Complement and coagulation cascades was found to be the most highly associated pathway, containing 50 of the total 283 peptides. These 50 peptides mapped to 17 different proteins (false discovery rate $=2.44^{*} 10^{-13}$; Table 3 ). Finally, functional analysis was repeated using only the 12 peptides significant at $\mathrm{q}<0.05$ rather than $\mathrm{q}<0.25$ (Supplemental Table 1) to assess whether they alone contributed to any known pathway; however, this did not reveal any significant pathway association.

Table 2

Functional pathway associations

\begin{tabular}{|llll|}
\hline $\begin{array}{l}\text { Kyoto Encyclopedia of Genes and Genomes } \\
\text { Pathway }\end{array}$ & $\begin{array}{l}\text { Protein } \\
\text { Count }\end{array}$ & p-value & $\begin{array}{l}\text { False Discovery } \\
\text { Rate }\end{array}$ \\
\hline $\begin{array}{l}\text { hsa04610: Complement and coagulation } \\
\text { cascades }\end{array}$ & 17 & $\begin{array}{l}1.82^{\star} 10^{-} \\
16\end{array}$ & $2.442^{\star} 10^{-13}$ \\
\hline hsa05020: Prion diseases & 8 & $\begin{array}{l}1.63^{\star} 10^{-} \\
07\end{array}$ & $1.835^{\star} 10^{-04}$ \\
\hline hsa05150: Staphylococcus aureus infection & 9 & $\begin{array}{l}3.85^{\star} 10^{-} \\
07\end{array}$ & $4.328^{\star} 10^{-04}$ \\
\hline hsa04514: Cell adhesion molecules (CAMs) & 11 & $\begin{array}{l}1.38^{\star} 10^{-} \\
05\end{array}$ & 0.015 \\
\hline hsa04142: Lysosome & & $\begin{array}{l}1.64^{\star} 10^{-} \\
04\end{array}$ & 0.183 \\
\hline hsa04512: ECM-receptor interaction & 9 & 0.0054 & 5.836 \\
\hline hsa05322: Systemic lupus erythematosus & 7 & 0.008 & 8.419 \\
\hline hsa05133: Pertussis & 6 & 0.016 & 16.723 \\
\hline hsa00511: Other glycan degradation & 5 & 0.022 & 22.428 \\
\hline
\end{tabular}

Table 2. A list of Kyoto Encyclopedia of Genes and Genomes pathways associated with subsets of the 182 proteins that contained significant peptides in our analysis. 
Table 3

Peptides with $\mathrm{q}<0.25$ for time-group interaction at six weeks in the linear mixed model

\begin{tabular}{|ll|}
\hline Protein Name & Number of Peptides with $\mathbf{q}<\mathbf{0 . 2 5}$ \\
\hline Complement C5 & 11 \\
\hline Plasma protease C1 inhibitor & 1 \\
\hline Complement C3 & 1 \\
\hline Complement C2 & 2 \\
\hline Complement factor B & 8 \\
\hline Kininogen 1 & 1 \\
\hline Complement C6 & 5 \\
\hline Complement C8b & 3 \\
\hline Plasminogen & 6 \\
\hline Complement C1s subunit & 1 \\
\hline Complement factor H & 1 \\
\hline Antithrombin-III & 2 \\
\hline Complement C9 & 1 \\
\hline Coagulation factor 5 & 3 \\
\hline Complement Factor I & 2 \\
\hline Fibrinogen & 1 \\
\hline Prekallikrein & 1 \\
\hline
\end{tabular}

Table 3: Proteins in the KEGG hsa04610: Complement and coagulation cascades pathway with $\mathrm{q}<0.25$ for time-group interaction in the linear mixed models.

To further study the role of complement in the pathogenesis of perioperative neurocognitive disorders, complement proteins with peptides that had trend-level significance $(q<0.25)$ in the linear mixed model (factors $\mathrm{C} 1, \mathrm{C} 1 \mathrm{~s}, \mathrm{C} 2, \mathrm{C} 3, \mathrm{C} 5, \mathrm{C} 6, \mathrm{C} 8 \mathrm{~b}, \mathrm{C} 9, \mathrm{~B}, \mathrm{H}$, and plasma protease $\mathrm{C} 1$ inhibitor) were examined further. Though none of the individual peptides or proteins showed a statistically significant difference in intensity between the POCD and non-POCD groups at any single time point, trends in complement peptide and protein intensities were revealed (Figs. 1-2, Supplement Figs. 1-11). Notably, even with high peptide intensity variance across each group, the mean preoperative intensities for all complement peptides were consistently lower in patients who developed POCD than those who did not. Despite no significant differences between groups at this timepoint for any individual peptide, the probability of all 36 
complement and related peptides randomly exhibiting this trend would be $0.5^{\wedge} 36$, or $1.455^{\star} 10^{-11}$. When clustered by protein, the probability of this pattern occurring in the 12 complement proteins by chance would be $0.5^{\wedge} 12$, or $2.441 * 10^{-4}$.

Additionally, the patients who developed POCD exhibited overall rising trends in all complement proteins except complement factor $\mathrm{H}$ from baseline to 6-week time points, while patients without POCD exhibited decreasing intensity trends across the entire set of complement proteins over this time frame. For example, complement $C 5$ was found to have 11 peptides approaching significance $(q<0.25)$ in our linear mixed model (Fig. 1A-L), with similar trends for peptides from both its alpha and beta subunits. Likewise, the five peptides from complement C6 (Fig. 2A-F), three peptides from complement C8b (Fig. 3A-D), and six of the eight peptides from complement factor B (Fig. 4A,C-H) with $q<0.25$ were found to have similar patterns of convergence across the three time points between patients with and without POCD. Peptides from complement C2 (Supplemental Fig. 1A-C), factor 1 (Supplemental Fig. 2A-C), C1s, C3, C9, and plasma protease $\mathrm{C} 1$ inhibitor (Supplemental Fig. 3A-J) also had similar trends. Among the noncomplement proteins in this pathway with trend-level significance at $\mathrm{q}<0.25$, fibrinogen (Supplemental Fig. 4A-B), antithrombin-III (Supplemental Fig. 5A-C), and kallikrein (Supplemental Fig. 6A-B) exhibited this convergence pattern, while kininogen-1 (Supplemental Fig. 7A-B), plasminogen (Supplemental Fig. 8A-G), and coagulation factor $V$ (Supplemental Fig. 9A-D) did not.

\section{Discussion}

This pilot study represents one of the first unbiased proteomic analyses on pre- and postoperative CSF samples from patients with perioperative neurocognitive disorders compared to controls. This approach offers a powerful tool for characterizing CSF protein content in the perioperative setting and has the potential to identify pathways involved in the mechanisms underlying POCD, delirium and other perioperative neurocognitive disorders. We identified peptides from 11 proteins with statistically significant intensity changes $(q<0.05)$ in our FDR-adjusted linear mixed model, and pathway analysis revealed trend-level differences in 50 peptides from 17 complement and coagulation-related factors, suggesting a possible role for these pathways in POCD pathogenesis. Since we planned this study to evaluate the CSF proteome without focusing specifically on either these 11 proteins or the complement pathway, our findings illustrate the strength of unbiased CSF proteomic analyses for identifying potential "unknown unknowns" in the pathogenesis of perioperative neurocognitive disorders. Additionally, our findings on the variability of CSF peptide levels in older surgical patients may prove useful for guiding power calculations when planning future studies.

We identified 12 peptides from 11 proteins that satisfied the stringent significance threshold of $\mathrm{q}<0.05$ (Supplemental Table 1) in our linear mixed model examining an interaction between groups (POCD vs no POCD) and postoperative time points. Several of these 11 proteins have been previously implicated in other neurocognitive disorders. First, cystatin $\mathrm{C}$ appears to play a neuroprotective role in Alzheimer's disease, possibly through inhibition of cerebral amyloidosis[51, 52]. Furthermore, low cystatin $C$ levels and certain cystatin $\mathrm{C}$ polymorphisms have been identified as predisposing factors to Alzheimer's disease 
(reviewed)[53] and contribute to poor cognitive outcomes in Parkinson's disease[54], after ischemic strokes[55], and in HIV-associated neurocognitive disorder[56]. Similarly, multiple peptides representing the copper and iron-handling protein ceruloplasmin were found to vary significantly between groups at $q$ $<0.05$. Copper storage and regulation abnormalities have been implicated in the pathogenesis of Alzheimer's disease (reviewed) [57] and HIV-associated neurocognitive disorder[58], and alterations in ceruloplasmin activity have been associated with increased Alzheimer's disease risk $[59,60]$. Finally, the axonal secretory sorting receptor secretogranin-III, represented by a single peptide with $q<0.05$, has been implicated in the mechanisms driving amyloid-mediated neurodegeneration in Alzheimer's disease[61]. To our knowledge, these proteins have not previously been previously associated with POCD. Targeted proteomic studies to determine their roles in perioperative neurocognitive disorders are thus warranted.

Pathway analysis on peptides that showed trend-level significance with $\mathrm{q}<0.25$ identified a significant role for the complement and coagulations factors pathway(s). The hypothesis that complement plays a role in perioperative neurocognitive disorders aligns with current animal models of surgery-induced neuroinflammation and cognitive decline[62]. Complement regulates brain development and homeostasis by driving microglial synaptic phagocytosis[63], and in murine models, complement-dependent synaptic pruning is critical for optimizing cognitive performance by reducing excessive synapse numbers that can cause epilepsy[64,65]. However, abnormal CNS complement activity has also been revealed in several neurocognitive disease states as a neuroinflammatory trigger for microglial activation and neuronal damage[66-68]. A role for complement in perioperative neurocognitive disorders would fit the theory that these disorders are driven by neuroinflammation[1, 69]. Indeed, murine model studies have shown that complement C3 levels, an initiator of the complement cascade, and levels of the receptor for its cleavage product (C3aR) are elevated after orthopedic surgery, and these increases have been shown to contribute to cognitive dysfunction in mouse POCD models[62]. Similarly, elevated baseline CSF C3 levels have been associated with higher rates of postoperative delirium in human patients[70], and critically-ill patients with delirium have been found to exhibit upregulated CSF complement levels[71]. Our results align with these prior studies to support a role for dysregulated complement in human perioperative neurocognitive disorders.

Complement pathway activation has been observed in peripheral blood after cardiac surgery involving cardiopulmonary bypass[72], which prompted a study on the effect of the anti-C5 monoclonal antibody pexelizumab on POCD rates following coronary artery bypass graft surgery[73]. This study measured changes in cognitive function from before surgery to 4 and 30 days after surgery, and found reduced visuospatial cognitive deficits at both time points in patients who received pexelizumab compared to controls[73]. Pexelizumab had no effect on global cognition at either timepoint, though this negative finding is unsurprising for two reasons: first, it was administered only for 24 hours and has a relatively short half-life (20-27 hours)[74]. Second, the penetration of monoclonal antibodies across the bloodbrain barrier is limited[75], and it is unknown whether the mild increase in blood-brain barrier permeability due to anesthesia[76] would permit sufficient CNS access for pexelizumab to effectively block complement activity within the brain. Thus, a proper test of the role of complement activation in POCD 
will require future studies utilizing complement inhibitors that cross the blood-brain barrier and which have sufficient half-lives.

Our ability to identify additional proteins and pathways associated with POCD in this pilot study was limited by a high degree of variance in peptide intensities among the participants, and there was no peptide that showed intensity differences between groups at any single time point. Despite this limitation, analysis of our results revealed two noteworthy trends. First, among the all complement proteins containing peptides with significantly different intensities in our mixed models, the mean baseline peptide levels were lower in patients who later developed POCD. Second, over the course of six weeks, there was a clear trend toward convergence of these peptide intensities for all of the proteins except complement factor $\mathrm{H}$, which further diverged by the six-week time point. The consistency of these trends, despite high peptide intensity variance within groups, suggests that significant results will likely be detected in a larger cohort. Thus, the data collected in this study may prove useful for planning future studies using unbiased proteomic analyses on perioperative CSF samples. For example, a power analysis on complement $\mathrm{C} 5$ and C6 peptide intensities calculating for $\mathrm{a}=0.0001$ to account for multiple testing indicates that group sizes of $>31$ patients would have $80 \%$ power to reveal significant differences between baseline peptide intensities (calculated for $\mathrm{C} 6$ peptide KALQEYAAK with a difference of $1.419 * 10^{7}$ between means). Group sizes of 108 would have at least $80 \%$ power to detect baseline intensity differences in half of the $\mathrm{C} 5$ and C6 peptides with $\mathrm{q}<0.25$ in our linear mixed model.

In addition to the complement peptides that differed between groups, several non-complement factors with known pro-inflammatory and/or hemostatic functions were identified by our linear mixed models as trending toward significance $(q<0.25)$ between the patients with versus without POCD over the six-week period. Notably, fibrinogen and its cleavage products are known to contribute to inflammation in the CNS by a variety of mechanisms including microglial activation[77, 78], neuronal damage[79], interactions with beta-amyloid[80], and disruption of the blood-brain barrier[81]. In fact, alterations in CNS fibrinogen biology have been implicated in the pathogenesis of neurological, neurocognitive, and psychiatric disorders including multiple sclerosis[82], traumatic brain injury[83], Alzheimer's disease[78, 84], and depression[85]. Likewise, coagulation factor $\mathrm{V}$, a central mediator of hemostasis, has been previously linked to delirium pathogenesis[33]. Further, plasminogen has been shown to potentiate neuroinflammation[86, 87] and Alzheimer's disease-related pathology[86], and elevated serum kininogen has been associated with depression[85]. As with complement, our data suggest a relationship between POCD and dysregulation of these inflammatory and thromboactive factors.

Several limitations apply to this study. First, although the CSF analyses presented here suggest differential changes in peptides levels from complement and coagulation-related proteins between patients with versus without POCD, it is possible that these changes could reflect non-causal associations. In essence, these pathways may be markers of POCD without playing an active role in causing it. Second, like other mass spectrometry-based analyses, the intensities measured in this study reflect relative peptide levels rather than quantitative concentration measurements. Thus, while our unbiased approach has identified candidate proteins with suspected involvement in POCD, precise protein 
levels and inter-protein comparisons will require additional targeted studies (i.e. proteomic studies with internal controls designed for precise quantification). Third, the results of this preliminary study are by no means definitive, as larger future studies are needed to more thoroughly assess the role of these proteins and pathways in POCD and/or other perioperative neurocognitive disorders. Fourth, it is unclear whether the differential changes in CSF protein levels observed here are driven primarily by changes in expression, activity, or turnover initiated within the CNS, versus peripheral inflammation and activation of the coagulation and complement cascades after surgery that crosses the blood-brain barrier into the CNS. Further research comparing postoperative changes in both the CSF and plasma proteomes at multiple simultaneous time points may help evaluate these two different possibilities.

\section{Conclusions}

Our study demonstrates the feasibility of using unbiased CSF proteomic analyses to explore the mechanisms underlying perioperative neurocognitive disorders and provides preliminary evidence that complement and coagulation pathway activation contributes to POCD pathogenesis. Additionally, the data reported here may guide sample size calculations, allowing future studies to definitively investigate the role of CSF complement and coagulation pathway changes in POCD and other perioperative neurocognitive disorders.

\section{List Of Abbreviations}

POCD, Postoperative cognitive dysfunction; AD, Alzheimer's disease; CSF, Cerebrospinal fluid; KEGG, Kyoto Encyclopedia of Genes and Genomes; $\mathrm{CCl}$, Continuous cognitive index

\section{Declarations}

Ethics approval and consent to participate: This study was approved by the Duke University Medical Center Institutional Review Board. The participants in this study were part of a parent study registered with clinicaltrials.gov (NCT01993836). All subjects gave written informed consent for inclusion in this study.

Consent for publication: Not applicable

Availability of data and materials: The primary data from this manuscript is available in the supplemental materials.

Competing interests:

KVD: No interests to disclose.

WQ: No interests to disclose.

YL: No interests to disclose. 
VC: No interests to disclose.

$\mathrm{AH}$ : No interests to disclose.

SH: No interests to disclose.

JWT: No interests to disclose.

MAM: No interests to disclose.

$\mathrm{JH}:$ No interests to disclose.

MC: No interests to disclose.

JL: Acknowledges serving on advisory or steering committees for Instrumentation Labs, Merck, and Octapharma.

KG: Acknowledges serving as a remunerated consultant for Uptodate $\AA^{\circledR}$ in the section for coagulation, blood management and reversal agents. He receives grant support from NIH T32GM008600 and Duke Health, and has received previous grant support from Octapharma.

QQ: No interests to disclose.

MD: Acknowledges a Research Fellowship Grant from the Foundation of Anesthesia Education and Research Society.

LA: No interests to disclose.

NT: No interests to disclose.

EM: No interests to disclose.

JB: No interests to disclose.

JM: No interests to disclose.

MB: Acknowledges funding from Minnetronix Inc, for a project unrelated to the subject matter of this study and has received material support (i.e. EEG monitors) for a postoperative recovery study in older adults from Masimo. MB has also received legal consulting fees related to postoperative cognition in older adults.

Funding: This study was supported by a Duke Anesthesiology DREAM Innovation Grant (to MB), NIH R03 AG050918 (to MB), NIH T32GM008600, and a mentored research award from the International Anesthesia Research Society (to MB). MB also acknowledges additional support from NIH grants K76AG057022, P30AG028716, and UH3AG056925, and from the Duke Anesthesiology Department. 
Author contributions: Miles Berger and Joseph Mathew conceived of this project. Arthur Moseley, Sarah Hiles, and Will Thompson performed the proteomic analyses. Yi-Ju Li, Wenjing Qi, and Mary Cooter conducted the statistical analyses. Jessica Hu performed the APOE genotyping. Keith VanDusen and Miles Berger analyzed data and wrote the manuscript. Victor Cai, Ashley Hall, Kamrouz Ghadimi, Jerrold Levy, Quinton Quinones, Michael Devinney, Leah Acker, Eugene Moretti, Jeffrey Browndyke, and Joseph Mathew assisted with manuscript preparation. All authors reviewed and approved the final manuscript.

Acknowledgements: We thank all of the patients who participated in the MADCO-PC study.

\section{References}

1. Berger M, Nadler JW, Browndyke J, Terrando N, Ponnusamy V, Cohen HJ, et al. Postoperative Cognitive Dysfunction: Minding the Gaps in Our Knowledge of a Common Postoperative Complication in the Elderly. Anesthesiology clinics. 2015;33(3):517-50.

2. Evered L, Silbert B, Knopman DS, Scott DA, DeKosky ST, Rasmussen LS, et al. Recommendations for the nomenclature of cognitive change associated with anaesthesia and surgery-2018. Can J Anaesth. 2018;65(11):1248-57.

3. Berger M, Burke J, Eckenhoff R, Mathew J. Alzheimer's Disease, Anesthesia, and Surgery: A Clinically Focused Review. Journal of cardiothoracic and vascular anesthesia. 2014;28(6):1609-23.

4. Phillips-Bute B, Mathew JP, Blumenthal JA, Grocott HP, Laskowitz DT, Jones RH, et al. Association of neurocognitive function and quality of life 1 year after coronary artery bypass graft (CABG) surgery. Psychosom Med. 2006;68(3):369-75.

5. Newman MF, Grocott HP, Mathew JP, White WD, Landolfo K, Reves JG, et al. Report of the substudy assessing the impact of neurocognitive function on quality of life 5 years after cardiac surgery. Stroke. 2001;32(12):2874-81.

6. Newman MF, Kirchner JL, Phillips-Bute B, Gaver V, Grocott H, Jones RH, et al. Longitudinal assessment of neurocognitive function after coronary-artery bypass surgery. The New England journal of medicine. 2001;344(6):395-402.

7. Monk TG, Weldon BC, Garvan CW, Dede DE, van der Aa MT, Heilman KM, et al. Predictors of cognitive dysfunction after major noncardiac surgery. Anesthesiology. 2008;108(1):18-30.

8. Cullen KA, Hall MJ, Golosinskiy A. Ambulatory surgery in the United States, 2006. National health statistics reports. 2009(11):1-25.

9. Calsolaro V, Edison P. Neuroinflammation in Alzheimer's disease: Current evidence and future directions. Alzheimers Dement. 2016;12(6):719-32.

10. Ramaglia V, Hughes TR, Donev RM, Ruseva MM, Wu X, Huitinga I, et al. C3-dependent mechanism of microglial priming relevant to multiple sclerosis. Proceedings of the National Academy of Sciences. 2012;109(3):965.

11. Fominykh V, Brylev L, Gaskin V, Luzin R, Yakovlev A, Komoltsev I, et al. Neuronal damage and neuroinflammation markers in patients with autoimmune encephalitis and multiple sclerosis. Metab 
Brain Dis. 2019;34(5):1473-85.

12. Terrando N, Monaco C, Ma D, Foxwell BM, Feldmann M, Maze M. Tumor necrosis factor-alpha triggers a cytokine cascade yielding postoperative cognitive decline. Proceedings of the National Academy of Sciences of the United States of America. 2010;107(47):20518-22.

13. Hirsch J, Vacas S, Terrando N, Yuan M, Sands LP, Kramer J, et al. Perioperative cerebrospinal fluid and plasma inflammatory markers after orthopedic surgery. Journal of neuroinflammation. 2016;13(1):211.

14. Tang JX, Baranov D, Hammond M, Shaw LM, Eckenhoff MF, Eckenhoff RG. Human Alzheimer and inflammation biomarkers after anesthesia and surgery. Anesthesiology. 2011;115(4):727-32.

15. Terrando N, Eriksson LI, Ryu JK, Yang T, Monaco C, Feldmann M, et al. Resolving postoperative neuroinflammation and cognitive decline. Ann Neurol. 2011;70(6):986-95.

16. Mietani K, Sumitani M, Ogata T, Shimojo N, Inoue R, Abe H, et al. Dysfunction of the blood-brain barrier in postoperative delirium patients, referring to the axonal damage biomarker phosphorylated neurofilament heavy subunit. PloS one. 2019;14(10):e0222721.

17. Tang JX, Mardini F, Janik LS, Garrity ST, Li RQ, Bachlani G, et al. Modulation of murine Alzheimer pathogenesis and behavior by surgery. Annals of surgery. 2013;257(3):439-48.

18. Berger M, Nadler JW, Friedman A, McDonagh DL, Bennett ER, Cooter M, et al. The Effect of Propofol Versus Isoflurane Anesthesia on Human Cerebrospinal Fluid Markers of Alzheimer's Disease: Results of a Randomized Trial. Journal of Alzheimer's disease : JAD. 2016;52(4):1299-310.

19. Berger M, Ponnusamy V, Greene N, Cooter M, Nadler JW, Friedman A, et al. The Effect of Propofol vs. Isoflurane Anesthesia on Postoperative Changes in Cerebrospinal Fluid Cytokine Levels: Results from a Randomized Trial. Frontiers in Immunology. 2017;8(1528).

20. Xie Z, McAuliffe S, Swain CA, Ward SAP, Crosby CA, Zheng H, et al. Cerebrospinal fluid a $\beta$ to tau ratio and postoperative cognitive change. Annals of surgery. 2013;258(2):364-9.

21. Cunningham EL, McGuinness B, McAuley DF, Toombs J, Mawhinney T, O'Brien S, et al. CSF Betaamyloid 1-42 Concentration Predicts Delirium Following Elective Arthroplasty Surgery in an Observational Cohort Study. Annals of surgery. 2019;269(6):1200-5.

22. Evered L, Silbert B, Scott DA, Ames D, Maruff P, Blennow K. Cerebrospinal Fluid Biomarker for Alzheimer Disease Predicts Postoperative Cognitive Dysfunction. Anesthesiology. 2016;124(2):35361.

23. Rush J, Moritz A, Lee KA, Guo A, Goss VL, Spek EJ, et al. Immunoaffinity profiling of tyrosine phosphorylation in cancer cells. Nat Biotechnol. 2005;23(1):94-101.

24. Wang M, Beckmann ND, Roussos P, Wang E, Zhou X, Wang Q, et al. The Mount Sinai cohort of largescale genomic, transcriptomic and proteomic data in Alzheimer's disease. Sci Data. 2018;5:180185-.

25. Johnson ECB, Dammer EB, Duong DM, Yin L, Thambisetty M, Troncoso JC, et al. Deep proteomic network analysis of Alzheimer's disease brain reveals alterations in RNA binding proteins and RNA splicing associated with disease. Molecular Neurodegeneration. 2018;13(1):52. 
26. Ringman JM, Schulman H, Becker C, Jones T, Bai Y, Immermann F, et al. Proteomic changes in cerebrospinal fluid of presymptomatic and affected persons carrying familial Alzheimer disease mutations. Archives of neurology. 2012;69(1):96-104.

27. van der Ende EL, Meeter LH, Stingl C, van Rooij JGJ, Stoop MP, Nijholt DAT, et al. Novel CSF biomarkers in genetic frontotemporal dementia identified by proteomics. Annals of clinical and translational neurology. 2019;6(4):698-707.

28. Umoh ME, Dammer EB, Dai J, Duong DM, Lah JJ, Levey Al, et al. A proteomic network approach across the ALS-FTD disease spectrum resolves clinical phenotypes and genetic vulnerability in human brain. EMBO Mol Med. 2018;10(1):48-62.

29. Henderson MX, Chung CH, Riddle DM, Zhang B, Gathagan RJ, Seeholzer SH, et al. Unbiased Proteomics of Early Lewy Body Formation Model Implicates Active Microtubule Affinity-Regulating Kinases (MARKs) in Synucleinopathies. The Journal of neuroscience : the official journal of the Society for Neuroscience. 2017;37(24):5870-84.

30. Guha D, Lorenz DR, Misra V, Chettimada S, Morgello S, Gabuzda D. Proteomic analysis of cerebrospinal fluid extracellular vesicles reveals synaptic injury, inflammation, and stress response markers in HIV patients with cognitive impairment. Journal of neuroinflammation. 2019;16(1):254-.

31. Fernandez-Irigoyen J, Zelaya MV, Santamaria E. Applying mass spectrometry-based qualitative proteomics to human amygdaloid complex. Front Cell Neurosci. 2014;8:80.

32. Muraoka S, Jedrychowski MP, Tatebe H, DeLeo AM, Ikezu S, Tokuda T, et al. Proteomic Profiling of Extracellular Vesicles Isolated From Cerebrospinal Fluid of Former National Football League Players at Risk for Chronic Traumatic Encephalopathy. Frontiers in neuroscience. 2019;13:1059-.

33. Han Y, Chen W, Song Y, Yuan Y, Li Z, Zhou Y, et al. Proteomic Analysis of Preoperative CSF Reveals Risk Biomarkers of Postoperative Delirium. Front Psychiatry. 2020;11:170.

34. Giattino CM, Gardner JE, Sbahi FM, Roberts KC, Cooter M, Moretti E, et al. Intraoperative Frontal Alpha-Band Power Correlates with Preoperative Neurocognitive Function in Older Adults. Frontiers in systems neuroscience. 2017;11:24.

35. Mathew JP, White WD, Schinderle DB, Podgoreanu MV, Berger M, Milano CA, et al. Intraoperative magnesium administration does not improve neurocognitive function after cardiac surgery. Stroke. 2013;44(12):3407-13.

36. Berger M, Oyeyemi D, Olurinde MO, Whitson HE, Weinhold KJ, Woldorff MG, et al. The INTUIT Study: Investigating Neuroinflammation Underlying Postoperative Cognitive Dysfunction. Journal of the American Geriatrics Society. 2019.

37. McDonagh DL, Mathew JP, White WD, Phillips-Bute B, Laskowitz DT, Podgoreanu MV, et al. Cognitive function after major noncardiac surgery, apolipoprotein E4 genotype, and biomarkers of brain injury. Anesthesiology. 2010;112(4):852-9.

38. Klinger RY, Cooter M, Berger M, Podgoreanu MV, Stafford-Smith M, Ortel TL, et al. Effect of intravenous lidocaine on the transcerebral inflammatory response during cardiac surgery: a 
randomized-controlled trial. Canadian journal of anaesthesia $=$ Journal canadien d'anesthesie . 2016;63(11):1223-32.

39. Browndyke JN, Berger M, Smith PJ, Harshbarger TB, Monge ZA, Panchal V, et al. Task-related changes in degree centrality and local coherence of the posterior cingulate cortex after major cardiac surgery in older adults. Hum Brain Mapp. 2018;39(2):985-1003.

40. Klinger RY, James OG, Borges-Neto S, Bisanar T, Li Y-J, Qi W, et al. 18F-florbetapir Positron Emission Tomography-determined Cerebral $\beta$-Amyloid Deposition and Neurocognitive Performance after Cardiac Surgery. Anesthesiology. 2018;128(4):728-44.

41. Berger M, Murdoch DM, Staats JS, Chan C, Thomas JP, Garrigues GE, et al. Flow Cytometry Characterization of Cerebrospinal Fluid Monocytes in Patients With Postoperative Cognitive Dysfunction: A Pilot Study. Anesthesia and analgesia. 2019;129(5):e150-e4.

42. Smith PJ, Browndyke JN, Monge ZA, Harshbarger TB, James ML, Gaca JG, et al. Longitudinal Changes in Regional Cerebral Perfusion and Cognition After Cardiac Operation. The Annals of thoracic surgery. 2019;107(1):112-8.

43. Browndyke JN, Berger M, Harshbarger TB, Smith PJ, White W, Bisanar TL, et al. Resting-State Functional Connectivity and Cognition After Major Cardiac Surgery in Older Adults without Preoperative Cognitive Impairment: Preliminary Findings. Journal of the American Geriatrics Society. 2017;65(1):e6-e12.

44. Yang T, Xu G, Newton PT, Chagin AS, Mkrtchian S, Carlstrom M, et al. Maresin 1 attenuates neuroinflammation in a mouse model of perioperative neurocognitive disorders. $\mathrm{Br} \mathrm{J}$ Anaesth. 2019;122(3):350-60.

45. Nobuhara CK, Bullock WM, Bunning T, Colin B, Cooter M, Devinney MJ, et al. A protocol to reduce selfreported pain scores and adverse events following lumbar punctures in older adults. J Neurol. 2020.

46. Storey JD. The positive false discovery rate: a Bayesian interpretation and the q -value. Ann Statist. 2003;31(6):2013-35.

47. Benjamini Y, Hochberg Y. Controlling the False Discovery Rate: A Practical and Powerful Approach to Multiple Testing. Journal of the Royal Statistical Society: Series B (Methodological). 1995;57(1):289300.

48. Storey JD. A Direct Approach to False Discovery Rates. Journal of the Royal Statistical Society Series B (Statistical Methodology). 2002;64(3):479-98.

49. Huang da W, Sherman BT, Lempicki RA. Systematic and integrative analysis of large gene lists using DAVID bioinformatics resources. Nature protocols. 2009;4(1):44-57.

50. Huang da W, Sherman BT, Lempicki RA. Bioinformatics enrichment tools: paths toward the comprehensive functional analysis of large gene lists. Nucleic Acids Res. 2009;37(1):1-13.

51. Mi W, Pawlik M, Sastre M, Jung SS, Radvinsky DS, Klein AM, et al. Cystatin C inhibits amyloid- $\beta$ deposition in Alzheimer's disease mouse models. Nature Genetics. 2007;39(12):1440-2.

52. Sundelöf J, Arnlöv J, Ingelsson E, Sundström J, Basu S, Zethelius B, et al. Serum cystatin C and the risk of Alzheimer disease in elderly men. Neurology. 2008;71(14):1072-9. 
53. Kaur G, Levy E. Cystatin C in Alzheimer's disease. Front Mol Neurosci. 2012;5:79-.

54. Hu WD, Chen J, Mao CJ, Feng P, Yang YP, Luo WF, et al. Elevated Cystatin C Levels Are Associated with Cognitive Impairment and Progression of Parkinson Disease. Cogn Behav Neurol. 2016;29(3):144-9.

55. Guo D-X, Zhu Z-B, Zhong C-K, Bu X-Q, Chen L-H, Xu T, et al. Serum cystatin C levels are negatively correlated with post-stroke cognitive dysfunction. Neural regeneration research. 2020;15(5):922-8.

56. Kalayjian RC, Robertson KR, Albert JM, Fichtenbaum CJ, Brown TT, Taiwo BO. Plasma Cystatin C Associates With HIV-Associated Neurocognitive Disorder but Is a Poor Diagnostic Marker in Antiretroviral Therapy-Treated Individuals. J Acquir Immune Defic Syndr. 2019;81(2):e49-e54.

57. Sensi SL, Granzotto A, Siotto M, Squitti R. Copper and Zinc Dysregulation in Alzheimer's Disease. Trends Pharmacol Sci. 2018;39(12):1049-63.

58. Kallianpur AR, Gittleman H, Letendre S, Ellis R, Barnholtz-Sloan JS, Bush WS, et al. Cerebrospinal Fluid Ceruloplasmin, Haptoglobin, and Vascular Endothelial Growth Factor Are Associated with Neurocognitive Impairment in Adults with HIV Infection. Molecular neurobiology. 2019;56(5):3808-18.

59. Siotto M, Simonelli I, Pasqualetti P, Mariani S, Caprara D, Bucossi S, et al. Association Between Serum Ceruloplasmin Specific Activity and Risk of Alzheimer's Disease. Journal of Alzheimer's disease: JAD. 2016;50(4):1181-9.

60. Diouf I, Bush Al, Ayton S. Cerebrospinal fluid ceruloplasmin levels predict cognitive decline and brain atrophy in people with underlying $\beta$-amyloid pathology. Neurobiology of disease. 2020;139:104810.

61. Plá V, Paco S, Ghezali G, Ciria V, Pozas E, Ferrer I, et al. Secretory sorting receptors carboxypeptidase $E$ and secretogranin III in amyloid $\beta$-associated neural degeneration in Alzheimer's disease. Brain Pathol. 2013;23(3):274-84.

62. Xiong C, Liu J, Lin D, Zhang J, Terrando N, Wu A. Complement activation contributes to perioperative neurocognitive disorders in mice. Journal of neuroinflammation. 2018;15(1):254.

63. Schafer DP, Lehrman EK, Kautzman AG, Koyama R, Mardinly AR, Yamasaki R, et al. Microglia sculpt postnatal neural circuits in an activity and complement-dependent manner. Neuron. 2012;74(4):691705.

64. Shi Q, Colodner KJ, Matousek SB, Merry K, Hong S, Kenison JE, et al. Complement C3-Deficient Mice Fail to Display Age-Related Hippocampal Decline. The Journal of neuroscience : the official journal of the Society for Neuroscience. 2015;35(38):13029-42.

65. Chu Y, Jin X, Parada I, Pesic A, Stevens B, Barres B, et al. Enhanced synaptic connectivity and epilepsy in $\mathrm{C} 1 \mathrm{q}$ knockout mice. Proceedings of the National Academy of Sciences of the United States of America. 2010;107(17):7975-80.

66. Alawieh A, Langley EF, Tomlinson S. Targeted complement inhibition salvages stressed neurons and inhibits neuroinflammation after stroke in mice. Science translational medicine. 2018;10(441).

67. Hong S, Beja-Glasser VF, Nfonoyim BM, Frouin A, Li S, Ramakrishnan S, et al. Complement and microglia mediate early synapse loss in Alzheimer mouse models. Science (New York, NY). 2016;352(6286):712. 
68. Sekar A, Bialas AR, de Rivera H, Davis A, Hammond TR, Kamitaki N, et al. Schizophrenia risk from complex variation of complement component 4. Nature. 2016;530(7589):177-83.

69. Subramaniyan S, Terrando N. Neuroinflammation and Perioperative Neurocognitive Disorders. Anesthesia and analgesia. 2019;128(4):781-8.

70. Westhoff D, Witlox J, van Aalst C, Scholtens RM, de Rooij SE, van Munster BC, et al. Preoperative protein profiles in cerebrospinal fluid in elderly hip fracture patients at risk for delirium: A proteomics and validation study. BBA Clinical. 2015;4:115-22.

71. Poljak A, Hill M, Hall RJ, MacLullich AM, Raftery MJ, Tai J, et al. Quantitative proteomics of delirium cerebrospinal fluid. Transl Psychiatry. 2014;4(11):e477.

72. Chenoweth DE, Cooper SW, Hugli TE, Stewart RW, Blackstone EH, Kirklin JW. Complement activation during cardiopulmonary bypass: evidence for generation of C3a and C5a anaphylatoxins. The New England journal of medicine. 1981;304(9):497-503.

73. Mathew JP, Shernan SK, White WD, Fitch JC, Chen JC, Bell L, et al. Preliminary report of the effects of complement suppression with pexelizumab on neurocognitive decline after coronary artery bypass graft surgery. Stroke. 2004;35(10):2335-9.

74. Shernan SK, Fitch JCK, Nussmeier NA, Chen JC, Rollins SA, Mojcik CF, et al. Impact of pexelizumab, an anti-C5 complement antibody, on total mortality and adverse cardiovascular outcomes in cardiac surgical patients undergoing cardiopulmonary bypass. The Annals of Thoracic Surgery. 2004;77(3):942-9.

75. Yu YJ, Watts RJ. Developing Therapeutic Antibodies for Neurodegenerative Disease. Neurotherapeutics. 2013;10(3):459-72.

76. Khokhlov AP, Fetisova IG, Chekhonin VP, Malakhovsky VK. The changes in the permeability of the blood-brain barrier when under neurosurgical intervention. Mol Chem Neuropathol. 1993;20(3):197202.

77. Piers TM, East E, Villegas-Llerena C, Sevastou IG, Matarin M, Hardy J, et al. Soluble Fibrinogen Triggers Non-cell Autonomous ER Stress-Mediated Microglial-Induced Neurotoxicity. Frontiers in Cellular Neuroscience. 2018;12(404).

78. Merlini M, Rafalski VA, Rios Coronado PE, Gill TM, Ellisman M, Muthukumar G, et al. Fibrinogen Induces Microglia-Mediated Spine Elimination and Cognitive Impairment in an Alzheimer's Disease Model. Neuron. 2019;101(6):1099-108.e6.

79. Cortes-Canteli M, Mattei L, Richards AT, Norris EH, Strickland S. Fibrin deposited in the Alzheimer's disease brain promotes neuronal degeneration. Neurobiology of aging. 2015;36(2):608-17.

80. Cortes-Canteli M, Paul J, Norris EH, Bronstein R, Ahn HJ, Zamolodchikov D, et al. Fibrinogen and betaamyloid association alters thrombosis and fibrinolysis: a possible contributing factor to Alzheimer's disease. Neuron. 2010;66(5):695-709.

81. Ryu JK, McLarnon JG. A leaky blood-brain barrier, fibrinogen infiltration and microglial reactivity in inflamed Alzheimer's disease brain. J Cell Mol Med. 2009;13(9a):2911-25. 
82. Davalos D, Ryu JK, Merlini M, Baeten KM, Le Moan N, Petersen MA, et al. Fibrinogen-induced perivascular microglial clustering is required for the development of axonal damage in neuroinflammation. Nature communications. 2012;3:1227-.

83. Jenkins DR, Craner MJ, Esiri MM, DeLuca GC. Contribution of Fibrinogen to Inflammation and Neuronal Density in Human Traumatic Brain Injury. J Neurotrauma. 2018;35(19):2259-71.

84. Ahn HJ, Chen ZL, Zamolodchikov D, Norris EH, Strickland S. Interactions of beta-amyloid peptide with fibrinogen and coagulation factor XII may contribute to Alzheimer's disease. Curr Opin Hematol. 2017;24(5):427-31.

85. Kang G, Zhang Y, Liu R, Li R, Kang Q, Zhu X, et al. Fibrinogen and Kininogen are Potential Serum Protein Biomarkers for Depressive Disorder. Clin Lab. 2019;65(10).

86. Baker SK, Chen ZL, Norris EH, Revenko AS, MacLeod AR, Strickland S. Blood-derived plasminogen drives brain inflammation and plaque deposition in a mouse model of Alzheimer's disease.

Proceedings of the National Academy of Sciences of the United States of America. 2018;115(41):E9687-e96.

87. Baker SK, Chen Z-L, Norris EH, Strickland S. Plasminogen mediates communication between the peripheral and central immune systems during systemic immune challenge with lipopolysaccharide. Journal of neuroinflammation. 2019;16(1):172.

\section{Additional File Legends}

\section{Complement $\mathrm{C} 2 \mathrm{~b}$ peptide locations and intensity trends}

Supplemental Figure 1. (A) A map of complement C2 showing the locations of its two peptides with $\mathrm{q}<$ 0.25 in the linear mixed model, which are both derived from its C2a fragment. (B) Graphs comparing median complement C2 peptide intensities between POCD and non-POCD groups across all three time points. Vertical bars represent interquartile range.

\section{Complement factor I peptide locations and intensity trends}

Supplemental Figure 2. (A) A map of complement factor I indicating the locations of its two peptides at $q$ $<0.25$ in the linear mixed model. One peptide is derived from its heavy chain, and one form its light chain. (B) Graphs comparing median complement factor I peptide intensities between POCD and non-POCD groups across all three time points. Vertical bars represent interquartile range.

Complement $\mathrm{C} 1 \mathrm{~s}, \mathrm{C} 3, \mathrm{C}$, factor $\mathrm{H}$, and plasma protease $\mathrm{C} 1$ inhibitor peptide locations and intensity trends 
Supplemental Figure 3. (A) Maps of the complement proteins that contained only one peptide with with q $<0.25$ each: Complement C1s, C3, C9, factor $\mathrm{H}$, and Plasma Protease C1 inhibitor. (B) Graphs comparing the median intensities of each peptide between POCD and non-POCD groups across all three time points. Vertical bars represent interquartile range. Post-translational modifications: *Deamidation **Carbamidomethylation ${ }^{* *}$ Oxidation

\section{Fibrinogen peptide locations and intensity trends}

Supplemental Figure 4. (A) A map of the fibrinogen protein indicating the location of its peptide with $\mathrm{q}<$ 0.25 in the linear mixed model. (B) A graphs comparing median fibrinogen peptide intensities between POCD and non-POCD groups across all three time points. Vertical bars represent interquartile range.

\section{Antithrombin-III peptide locations and intensity trends}

Supplemental Figure 5. (A) A map of the antithrombin-III protein indicating the locations of its two peptides with $\mathrm{q}<0.25$ in the linear mixed model. (B) Graphs comparing the median intensities of antithrombin-III peptides between POCD and non-POCD groups across all three time points. Vertical bars represent interquartile range.

\section{Kallikrein peptide locations and intensity trends}

Supplemental Figure 6. (A) A map of kallikrein indicating the location of its peptide with $q<0.25$ in the linear mixed model. (B) A graph comparing the intensities of this antithrombin-III peptide between POCD and non-POCD groups across all three time points. Vertical bars represent interquartile range. Posttranslational modifications: ${ }^{*}$ Carbamidomethylation

\section{Kininogen-1 peptide locations and intensity trends}

Supplemental Figure 7. (A) A map of kininogen-1 indicating the locations of its peptide with with $q<0.25$ in the linear mixed model. (B) Graphs comparing the median intensities of this kininogen peptide between $P O C D$ and non-POCD groups across all three time points. Vertical bars represent interquartile range. Posttranslational modifications: ${ }^{*}$ Carbamidomethylation

\section{Plasminogen Peptide Locations and Intensity Trends}

Supplemental Figure 8. (A) A map of the plasminogen protein indicating the locations of its six peptides with $q<0.25$ in the linear mixed model. Two significant peptides were located on the plasminogen heavy chain and four were located on the light chain. (B) Graphs comparing the median intensities of kininogen significant peptides between POCD and non-POCD groups across all three time points. Vertical bars represent interquartile range. Post-translational modifications: ${ }^{\star *}$ Carbamidomethylation 


\section{Coagulation Factor V Peptide Locations and Intensity Trends}

Supplemental Figure 9. (A) A map of coagulation factor V indicating the locations of its three peptides with with $\mathrm{q}<0.25$ in the linear mixed model. One significant peptide was derived from its heavy chain, and two were found within its light chain. (B) Graphs comparing median complement factor I peptide intensities between POCD and non-POCD groups across all three time points. Vertical bars represent interquartile range.

\section{Figures}



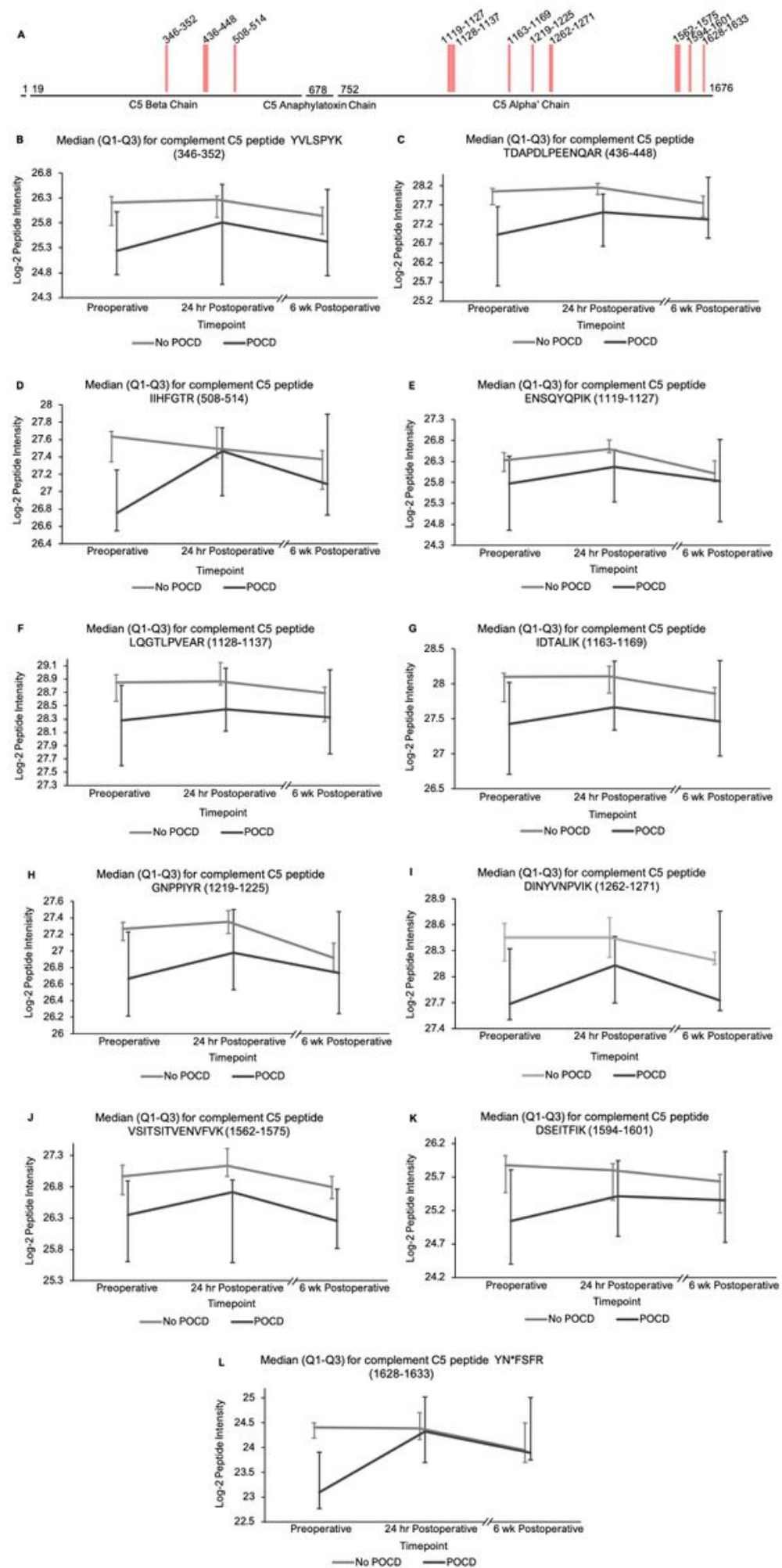

Figure 1

Complement C5 peptide locations and intensity trends (A) A map of complement C5 showing the locations of its 11 peptides with $(q<0.25)$ in the linear mixed models. Peptides $1-3$ are located on the beta subunit, and 4-11 are located on the alpha subunit. (B) Graphs comparing median C5 peptide intensities between POCD and non-POCD groups across all three time points. Vertical bars represent interquartile range. 


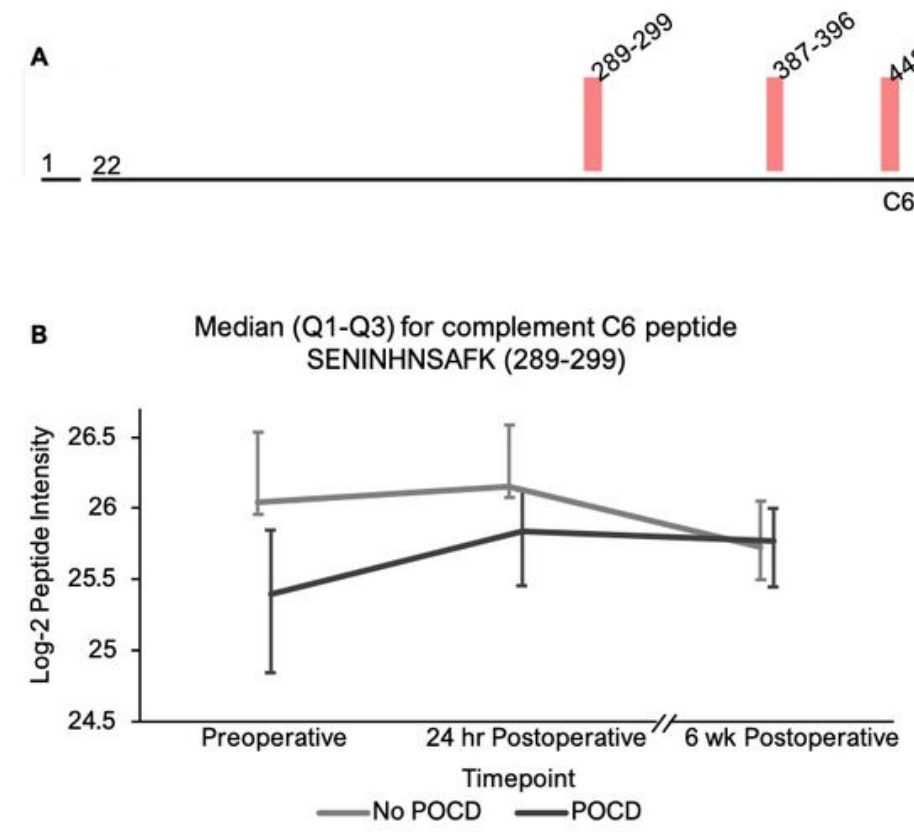

C6 Component
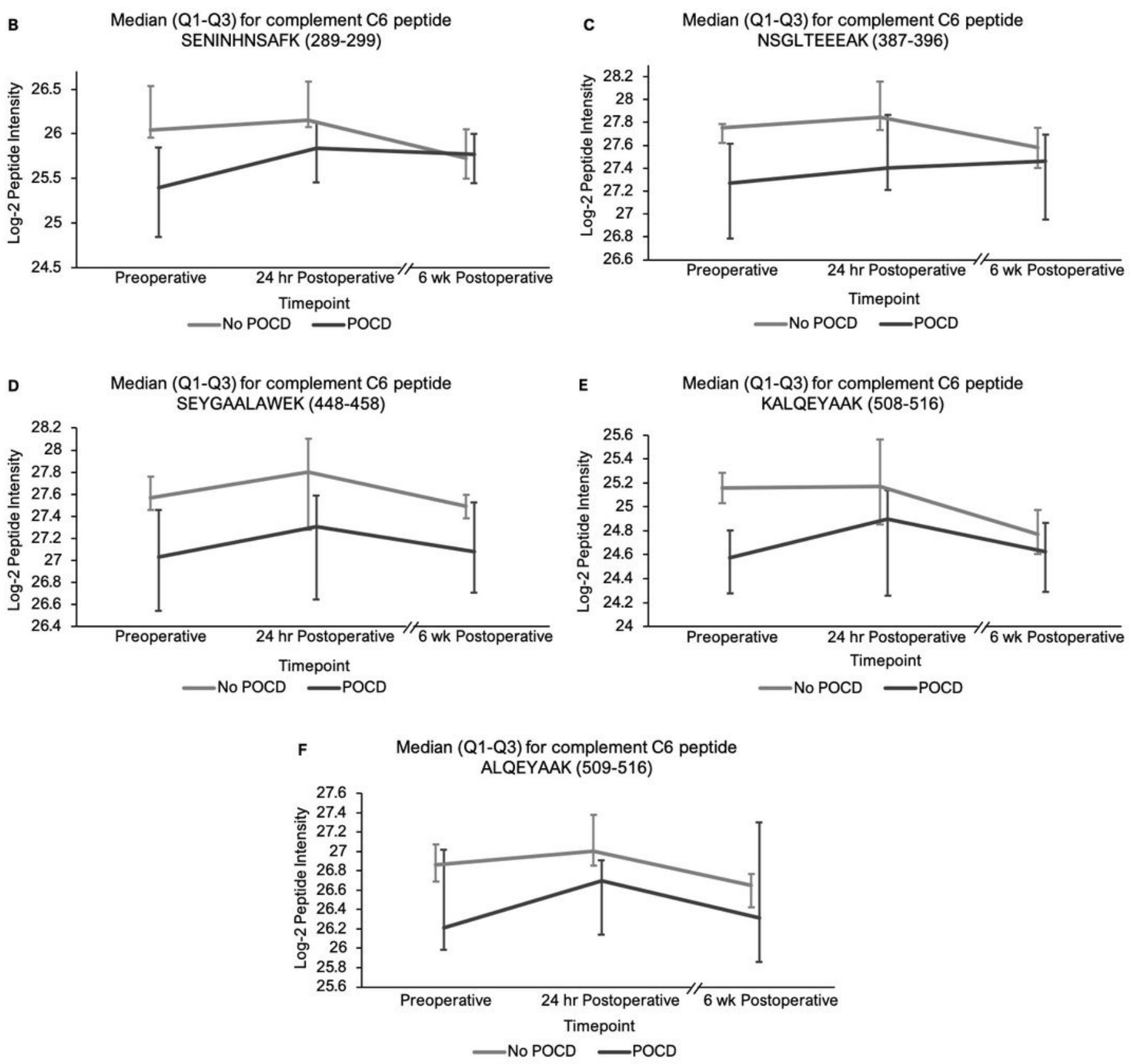

\section{Figure 2}

Complement $\mathrm{C} 6$ peptide locations and intensity trends (A) A map of complement $\mathrm{C} 6$ showing the locations of its five peptides with $\mathrm{q}<0.25$ in the linear mixed models. (B) Graphs comparing median $\mathrm{C} 6$ peptide intensities between POCD and non-POCD groups across all three time points. Vertical bars represent interquartile range. 

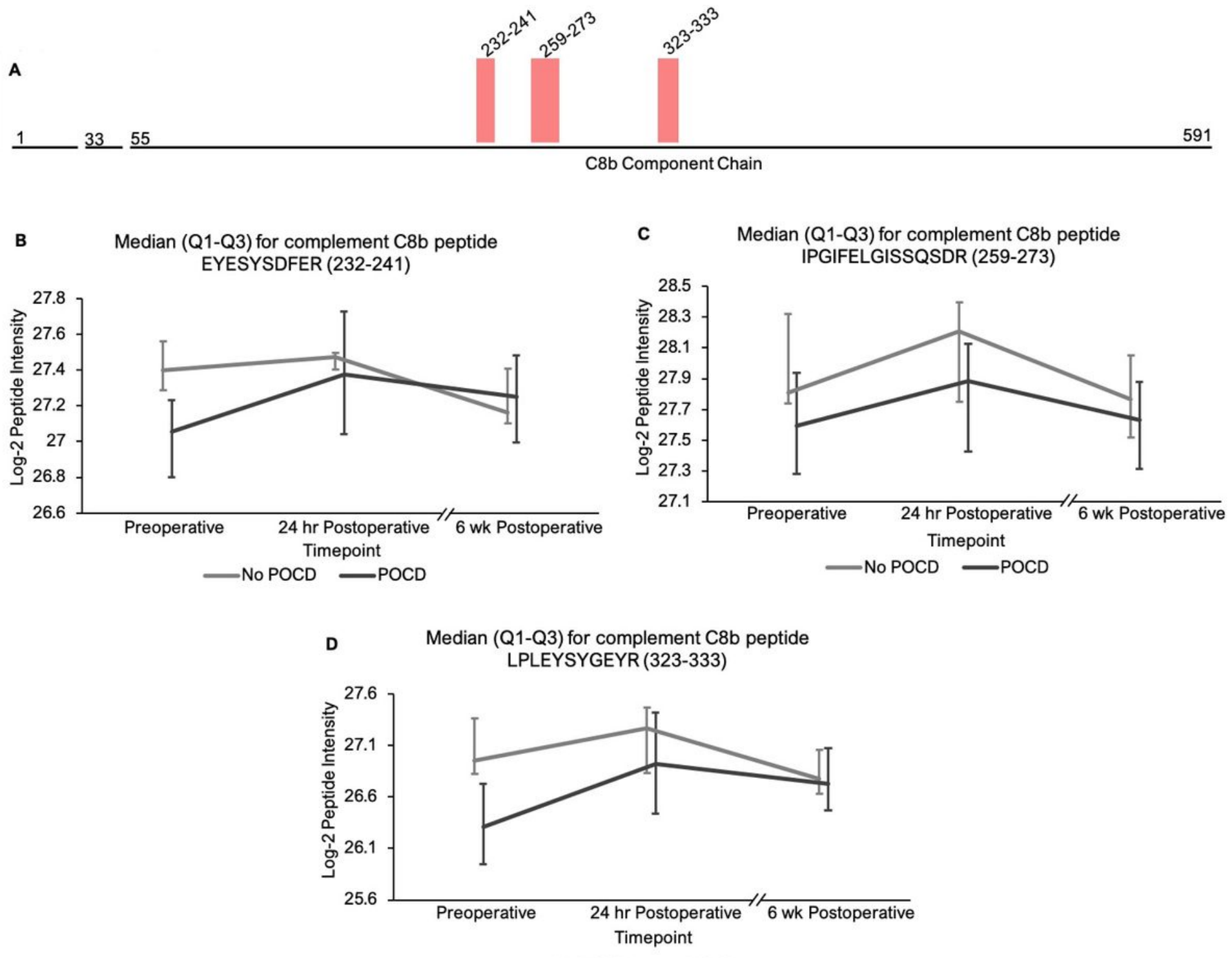

- No POCD $-\mathrm{POCD}$

\section{Figure 3}

Complement C8b peptide locations and intensity trends (A) A map of complement C8b showing the locations of its three peptides with $\mathrm{q}<0.25$ in the linear mixed model. (B) Graphs comparing median C8b peptide intensities between POCD and non-POCD groups across all three time points. Vertical bars represent interquartile range. 

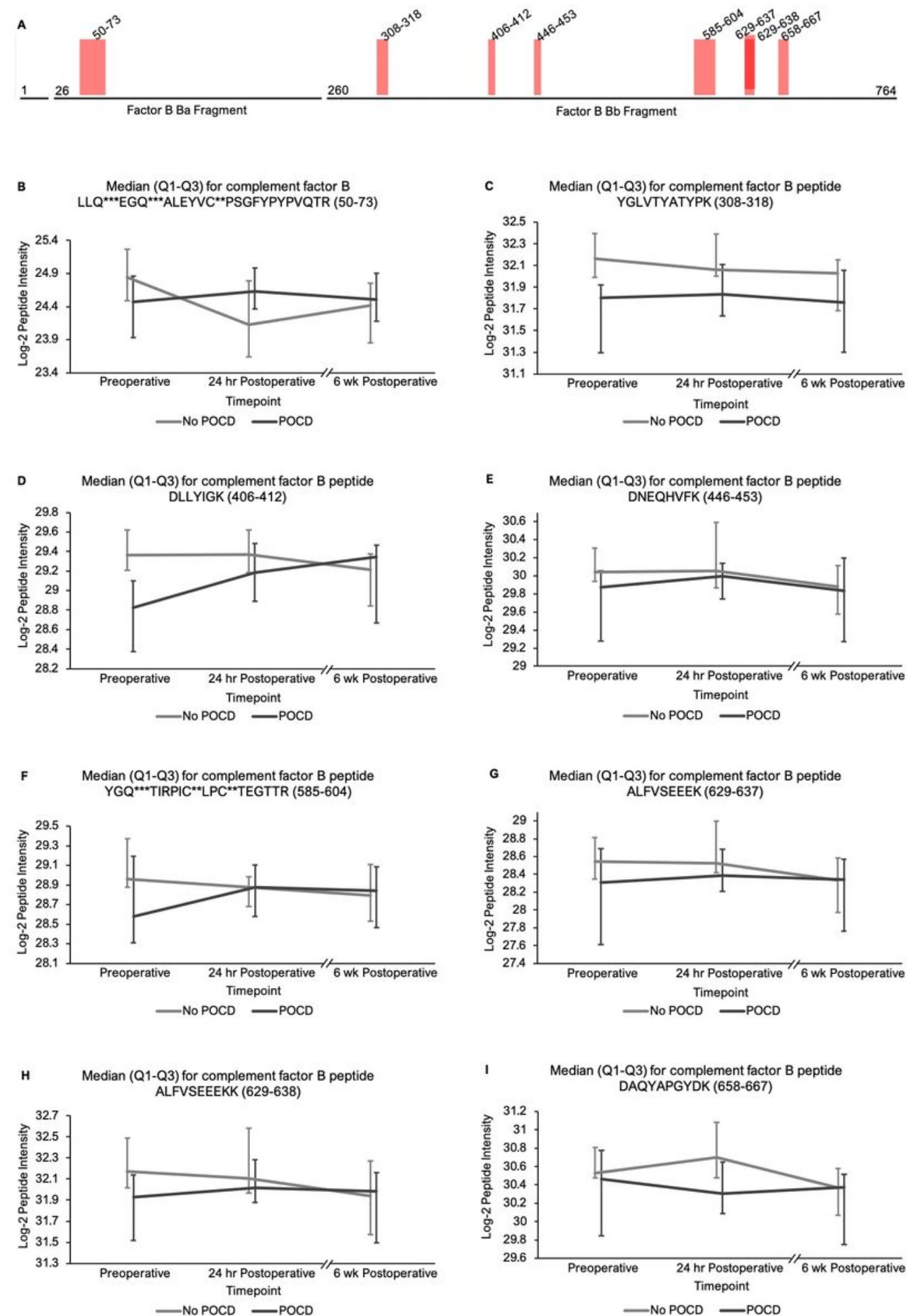

\section{Figure 4}

Complement factor B peptide locations and intensity trends (A) A map of complement factor B showing the locations of its eight peptides with $q<0.25$ in the linear mixed model. Seven of the eight peptides represent portions of its $\mathrm{Bb}$ fragment. (B) Graphs comparing median factor b peptide intensities between POCD and non-POCD groups across all three time points. Vertical bars represent interquartile range. Posttranslational modifications: *Deamidation ${ }^{* *}$ Carbamidomethylation ${ }^{* * *}$ Oxidation 


\section{Supplementary Files}

This is a list of supplementary files associated with this preprint. Click to download.

- SupplementalData.xlsx

- SupplementalData.xlsx

- SIFig9.jpg

- SIFig8.jpg

- SIFig7.jpg

- SIFig5.jpg

- SIFig6.jpg

- SIFig4.jpg

- SIFig3.jpg

- SIFig2.jpg

- SIFig1.jpg

- SupplementalTable1.pdf 